\title{
Urinary oxalate and glycolate excretion and plasma oxalate concentration
}

\author{
T M Barratt, G P Kasidas, I Murdoch, G A Rose
}

\begin{abstract}
The diagnosis of primary hyperoxaluria in young children is hampered by the lack of a reliable reference range for urinary oxalate excretion, especially in infants. We present data on urinary oxalate and glycolate excretion in 137 normal children, on the plasma oxalate concentration in 33 normal children and 53 with chronic renal failure, and on amniotic fluid oxalate concentration in 63 uncomplicated pregnancies. The urinary oxalate:creatinine molar ratios were log normally distributed: mean (range) values were $<1$ year $0.061(0.015-0.26), 1-5$ years 0.036 $(0.011-0.12), 5-12$ years $0.030(0.0059-0.15)$, and $>12$ years $0.013(0.0021-0.083)$. Geometric mean (range) plasma oxalate concentration in the normal children was $1.53(0.78-3.02)$ $\mu \mathrm{mol} / \mathrm{l}$ and was independent of age. The mean (SD) plasma oxalate:creatinine molar ratio in these normal children and 50 with chronic renal failure was $0.033(0.013)$, and was independent of age and renal function. Mean (SD) amniotic fluid oxalate concentration was 19.0 (4.3) $\mu \mathrm{mol} / 1$.
\end{abstract}

Primary hyperoxaluria type 1 is an inborn error of glyoxalate metabolism characterised by excessive production and urinary excretion of oxalate and glycolate. ${ }^{1}$ Two thirds of the cases present before the age of 5 years with calcium oxalate urolithiasis, and the disease usually runs a progressive course leading to end stage renal failure with systemic oxalosis before adulthood. It is important to diagnose the condition at an early stage so that therapeutic measures can be implemented to reduce the severity of the disease by modifying the risk factors associated with the deposition of calcium oxalate in the urinary tract and in the tissues.

There is, however, a paucity of information in the literature on the urinary excretion rates and plasma concentrations of oxalate and glycolate in young normal children. The report by Gibbs and Watts gives values for urinary oxalate excretion in a few normal children, the youngest of whom was 2.5 years of age, ${ }^{2}$ and the preliminary report of Kasidas and Rose presented only limited data on children under 1 year of age. ${ }^{3}$

Without reliable reference ranges the interpretation of urinary oxalate concentrations in young children has been uncertain. There is also some doubt about the appropriate correction of oxalate excretion for body size, and in any case the collection of accurately timed urine specimens from young children is notoriously difficult. In some cases a urine sample is unobtainable because of anuric renal failure: in these circumstances the association between the plasma concentrations of oxalate and creatinine has been used to support the diagnosis of primary hyperoxaluria, but again reference ranges are lacking. Finally, we considered the possibility of prenatal diagnosis of the disorder from amniotic fluid oxalate concentration, but good normal data were not available.

To address these problems we measured: (i) urinary oxalate:creatinine and (ii) glycolate: creatinine molar ratios in 137 'normal' children; (iii) plasma oxalate and creatinine concentrations in 33 'normal' children and 53 children with renal damage; and (iv) amniotic fluid oxalate concentration from 63 uncomplicated pregnancies.

\section{Patients and methods}

The group of 137 'normal' children were aged 0.1 to 17.0 years, and consisted of patients admitted to the Hospital for Sick Children, Great Ormond Street, London, for minor surgery unrelated to the urinary or gastrointestinal tract, their siblings, and the children of the staff and their friends. The height and weight were known in 92 of them. The urine sample obtained was the second in the morning-that is, the first sample passed after the overnight urine had been voided. Plasma was obtained from 33 of the children admitted for minor surgery who were having blood taken for clinical purposes and from 53 children attending the renal clinic of the hospital with various degrees of renal failure. Samples of amniotic fluid were obtained from 63 pregnant women at 16-18 weeks' gestation undergoing amniocentesis at $\mathrm{St}$ George's Hospital, London.

Oxalate concentration was measured enzymatically with immobilised oxalate oxidase, ${ }^{45}$ glycolate concentration with glycolate oxidase, ${ }^{6}$ and creatinine by Autoanalyser II using a modified Jaffé alkaline picrate reaction. For plasma and amniotic fluids, ultrafiltrates were prepared for analysis using Amicon Centriflo ultrafiltration membrane cones with molecular weight cut off of 25000 daltons.

Some of the data were log normally distributed: means, ranges, and correlations were therefore calculated on log transformed results. Surface area was calculated from the formula of Dubois and Dubois. ${ }^{7}$

\section{Results}

(i) URINE OXALATE:CREATININE MOLAR RATIO The urine oxalate:creatinine molar ratio (UOx: 


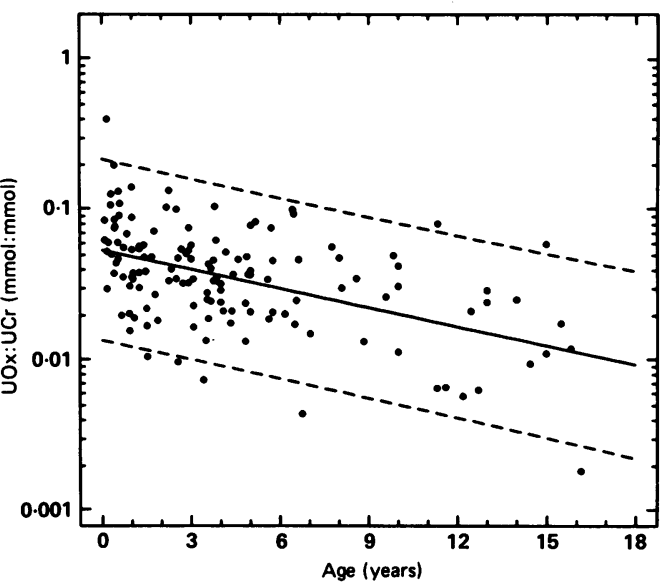

Figure 1 Urinary oxalate:creatinine molar ratio (UOx:UCr) compared with age: the regression equation is $\log (U O x: U C r)=-1.27-0.0425 \times$ age $($ years $)$ $(r=-0.50 ; p<0.0001)$

$\mathrm{UCr})$ decreased with age $(r=-0.50, \mathrm{p}<0.0001)$ (fig 1). The regression equation was:

$\log$ (UOx:UCr) $=-1 \cdot 27-0.0425 \times$ age (years)

Mean and ranges calculated on $\log$ transformed data are given in the table. UOx: $\mathrm{UCr}$ was significantly higher in infants than in older children $(p<0.001)$. In the 92 children for whom height and weight were known, $\log$ (UOx:UCr) correlated similarly with age $(r=-0.50)$, weight $(r=$ $-0.50)$, and surface area $(r=-0.48)$, better than with height $(r=-0.40)$, but the correlation coefficients were not significantly different from each other.

(ii) URINE GLYCOLATE:CREATININE MOLAR RATIO The urine glycolate:creatinine ratio (UGly:UCr) also declined with age $(r=-0.32, p<0.0005)$ (fig 2):

$\log$ (UGly:UCr) $=-1 \cdot 60-0.0223 \times$ age (years) The decline in UGly:UCr with age was less than that of UOx: UCr, and as a consequence, UOx: UGly also declined with age $(r=-0.27$, $\mathrm{p}<0.005$ ) (fig 3):

$\log$ (UOx:UGly) $=-0.323-0.0200 \times$ age $($ years $)$

(iii) PLASMa OXALATE AND CREATININE CONCENTRATIONS

In the healthy children the plasma oxalate (POx) concentration was independent of age $(r=0.09, p>0.1)$ or plasma creatinine concentration (PCr). Geometric mean (range) POx was $1.53(0.78-3.02) \mu \mathrm{mol} / 1$. When the children with renal disease were included there was a highly significant correlation between POx and

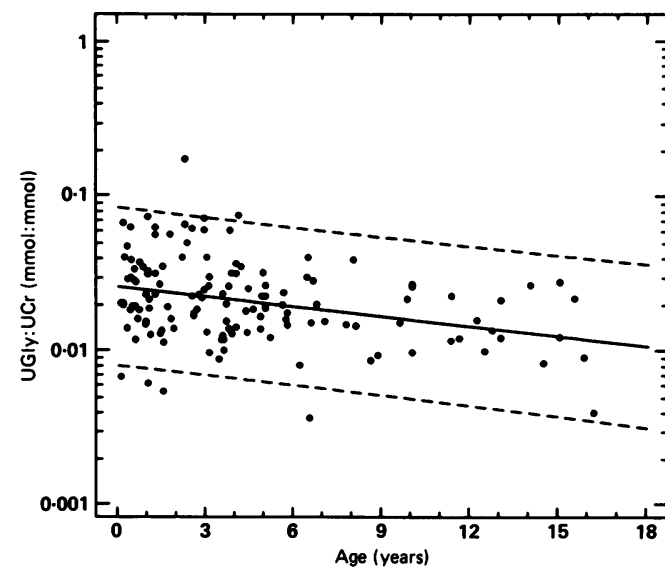

Figure 2 Urinary glycolate:creatinine molar ratio (UGly:UCr) compared with age: the regression equation is $\log (U G l y: U C r)=-1.60-0.0223 \times$ age (years) $(r=-0.32$, $p<0.0001$ ).

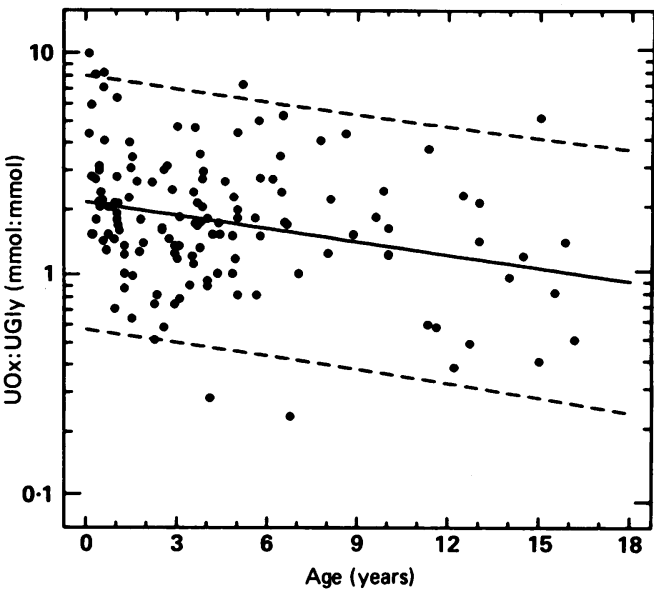

Figure 3 Urinary oxalate:glycolate molar ratio (UOx:UGly) compared with age: the regression equation is $\log (U O x: U G l y)=-0.323-0.0200 \times$ age (years) $(r=-0.27 ; p<0.005)$.

PCr, which were both $\log$ normally distributed ( $r=0.93, p<0.0001$ ) (fig 4). The regression equation was:

$\log \mathrm{POx}=-1.39+0.94 \times \log \mathrm{PCr}$

This association gives $\mathrm{POx}=1.6 \mu \mathrm{mol} / 1$ when $\mathrm{PCr}=50 \mu \mathrm{mol} / \mathrm{l}$, and $\mathrm{POx}=14.4 \mu \mathrm{mol} / \mathrm{l}$ when $\mathrm{PCr}=500 \mu \mathrm{mol} / \mathrm{l}$. The mean (SD) POx:PCr ratio was $0.033(0.013)$, was independent of age, and never exceeded 0.07 .

(iv) AMNIOTIC FLUID OXALATE CONCENTRATION Amniotic fluid oxalate concentration was approximately normally distributed with a mean (SD) of $19 \cdot 0(4 \cdot 3) \mu \mathrm{mol} / \mathrm{l}$.

Urinary oxalate and glycolate excretion

\begin{tabular}{lllll}
\hline & $<1$ year & $\begin{array}{l}1-<5 \text { years } \\
(n=67)\end{array}$ & $\begin{array}{l}5-<12 \text { years } \\
(n=31)\end{array}$ & $\begin{array}{c}>12 \text { years } \\
(n=12)\end{array}$ \\
\hline UOx:UCr (mmol:mmol) & 0.061 & 0.036 & 0.030 & 0.013 \\
UGly:UCr (mmol:mmol) & $(0.015-0.26)$ & $0.011-0.12)$ & $(0.0059-0.15)$ & $(0.0021-0.083)$ \\
UOx:UGly (mmol:mmol) & 0.024 & 0.023 & 0.016 & 0.013 \\
& $(0.0079-0.070)$ & $(0.0057-0.091)$ & $(0.0057-0.046)$ & $(0.0040-0.041)$ \\
& $(0.69-9.7)$ & 1.6 & 1.8 & 1.0 \\
& & $0.50-4.9)$ & $(0.41-8.1)$ & $(0.21-5 \cdot 1)$ \\
\hline
\end{tabular}

Mean (range) calculated on logged data. 


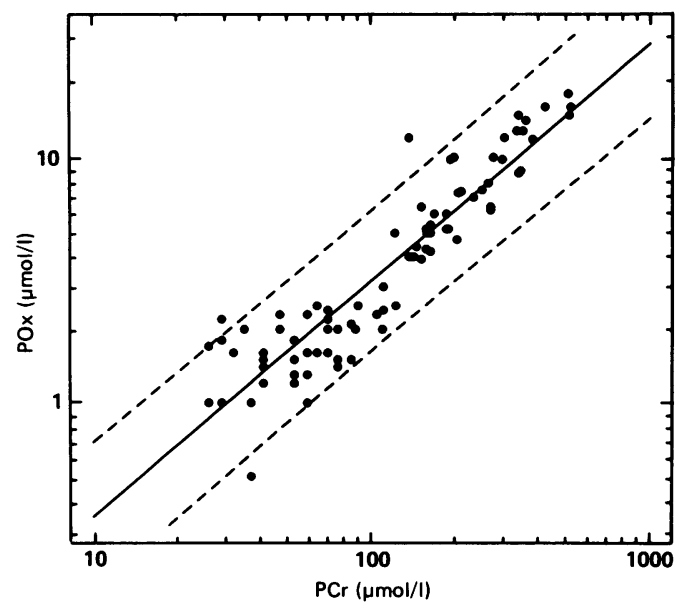

Figure 4 Plasma oxalate $(P O x)$ and creatinine $(P C r)$ concentrations: in the 'normal' children mean (SD) POx was $1.65(0.46) \mu \mathrm{mol} / \mathrm{l}$. Including the children with chronic renal failure the regression equation was: $\log P O x=-1 \cdot 39$

$+0.94 \times \log \operatorname{PCr}(r=0.93 ; p<0.0001)$.

\section{Discussion}

The reference ranges presented facilitate the diagnosis of hyperoxaluric states. $\mathrm{UOx}: \mathrm{UCr}$ is significantly higher in infants than in older children, clearly an important consideration in the evaluation of oxalate excretion in young children. Barratt et al argued that an inverse correlation of UOx:UCr with height was to be expected as oxalate excretion is proportional to body surface area (and thus to the square of height) whereas creatinine excretion is proportional to weight (and thus to the cube of height). ${ }^{8}$ Although there was a clear association between UOx:UCr and body size, a specific association with height was not observed. Also, UOx:UCr will also be influenced by factors independently affecting creatinine excretionfor example, reduced muscle bulk in malabsorption may result in low rates of creatinine excretion and thus spuriously high values for UOx:UCr.

UGly:UCr also declines with age, but less steeply than UOx:UCr, and UOx:UGly is higher in infants than in younger children. The same phenomenon is evident in primary hyperoxaluria $^{8}$; the reason is unknown, but it does suggest a greater risk of oxalate deposition in young children with disorders of oxalate metabolism. A raised value of $\mathrm{UOx}: \mathrm{UCr}$ with a normal value of UGly:UCr suggests enteric rather than primary hyperoxaluria.

Geometric mean POx was, at $1.53 \mu \mathrm{mol} / \mathrm{l}$, slightly lower but not significantly lower than adult values of $2.03(0.52) \mu \mathrm{mol} / 1 .^{5}$ It was inde- pendent of age, but rose in proportion to $\mathrm{PCr}$ in chronic renal failure in children as in adults. POx:PCr averaged 0.033 , and never exceeded $0.07^{9}$; values greater than this in patients with renal failure suggest the possibility of primary hyperoxaluria.

Rose et al reported a case where the prenatal diagnosis of primary hyperoxaluria was confirmed after the finding of a raised oxalate concentration of $110 \mu \mathrm{mol} / 1$ in the amniotic fluid. ${ }^{10}$ However, Leumann et al reported another case where primary hyperoxaluria was subsequently confirmed despite a normal level of oxalate in the amniotic fluid. ${ }^{11}$ With the elucidation of the primary enzyme defect, ${ }^{12}$ antenatal diagnosis by fetal liver biopsy has now become possible for type 1 primary hyperoxaluria. ${ }^{13}$ However, this is a highly specialised procedure not always available and does not detect type 2 hyperoxaluria. Hence there may still be a role for the measurement of amniotic fluid oxalate concentration, which needs to be further evaluated.

We thank Dr N McIntosh, Dr D Moncrieff, and Mrs T R Varma of the departments of child health and obstetrics at St George's Hospital for providing us with the samples of amniotic fluid. Dr I Murdoch was supported by the Kidney Research Aid Fund.

1 Williams HE, Smith LH. Primary hyperoxaluria. In: Stanbury JB, Wyngarden JB, Fredrickson DS, Goldstein 5th Ed. New York: McGraw Hill, 1983:204-28.

2 Gibbs DA, Watts RWE. The variation of urinary oxalate with age. $\mathcal{F}$ Lab Clin Med 1969;73:901-8.

3 Kasidas GP, Rose GA. The measurement of plasma oxalate and when it is useful. In: Vahlensieck W, Gasser G, eds. Pathogenese und Klinik der Harnsteine XII. Darmstadt: Pathogenese und Klinik der Harnst

4 Kasidas GP, Rose GA. Continuous-flow assay for urinary oxalate using immobilised oxalate oxidase. Ann Clin oxalate using immobilised

5 Kasidas GP, Rose GA. Measurement of plasma oxalate in healthy subjects and in patients with chronic renal failure using immobilised oxalate oxidase. Clin Chim Acta 1986; 154:49-58.

6 Kasidas GP, Rose GA. A new enzymatic method for the determination of glycolate in urine and plasma. Clin Chim Acta 1979;96:25-36.

7 Dubois D, Dubois EF. Clinical calorimetry: a formula to estimate the approximate surface area if height and weight be known. Arch Intern Med 1916;17:863-81.

8 Barratt TM, von Sperling V, Dillon MJ, Rose GA, Trompeter RS. Primary hyperoxaluria in children. In: Rose GA, ed. Oxalate metabolism in relation to urinary stone. London: Springer Verlag. 1988:83-101.

9 Constable AR, Joekes AM, Kasidas GP, O'Reagan P, Rose GA. Plasma level and renal clearance of oxalate in normal subjects and in patients with primary hyperoxaluria or subjects and in patients with primary hyperoxaluria or
chronic renal failure or both. Clin Sci 1979;56:299-304.

10 Rose GA, Arthur LJ, Chambers TL, Kasidas GP, Scott IV. Successful treatment of primary hyperoxaluria in a neonate.

11 Leumann E, Matasovic A, Niederwieser A. Primary hyperoxaluria type 1: oxalate and glycolate unsuitable for prenatal diagnosis. Lancet 1986;ii:340.

12 Danpure CJ, Jennings PR. Peroxisomal alanine:glyoxalate aminotransferase deficiency in primary hyperoxaluria type 1. FEBS Lett 1986;201:20-4.

13 Danpure CJ. Peroxisomal alanine:glyoxalate aminotransferase and prenatal diagnosis of primary hyperoxaluria type 1. Lancet 1986;ii:1168. 